\title{
PENGARUH PEMBERIAN LATIHAN SENAM AEROBIC HIGH IMPACT UNTUK MENINGKATKAN DAYA TAHAN KARDIORESPIRASI PADA SKIPPER ARUNG JERAM
}

\author{
I Putu Darmawijaya', I Made Gede Dwi Suputra², Agung Wahyu Permadi ${ }^{3}$ \\ 1,2,3 Program Studi Fisioterapi Universitas Dhyana Pura, Bali \\ Email: darmawijaya@undhirabali.ac.id.
}

\begin{abstract}
ABSTRAK
Kebugaran fisik menjadi syarat utama bagi seorang skipper dalam mengarungi sungai dengan kemampuan daya tahan paru jantung (kardiorespirasi) sebagai dasar ketahanan dari kerja otot dalam waktu yang lama. Salah satu latihan yang dapat meningkatkan daya tahan kardiorespirasi adalah senam aerobic high impact. Metode eksperimental diterapkan melalui latihan senam aerobic high impact dengan One Group Pretest-posttest Design dan dilaksanankan di My Adventure Rafting dengan jumlah sampel 21 orang selama 3 kali seminggu dalam 4 minggu penelitian. Berdasarkan uji paired t test didapatkan bahwa senam aerobic high impact berpengaruh terhadap peningkatan daya tahan kardiorespirasi. Dimana nilai probability (p) signifikan yaitu 0,000 yang berarti $0,000<0,05$ maka terdapat perbedaan yang bermakna.
\end{abstract}

Kata Kunci : Skipper, Daya Tahan Kardiorespirasi, Senam Aerobic High Impact

\begin{abstract}
Physical fitness is a key requirement for a skipper in the river, with the ability of cardiac endurance (cardiorespiration) as a basis for the endurance of muscle work for a long time. One exercise that can improve cardiorespiratory endurance is high impact aerobic exercise. The experimental method was applied through high impact aerobic exercise exercise with One Group Pretest-posttest Design and performed at My Adventure Rafting with a sample size of 21 people for 3 times a week in 4 weeks of research. Based on paired t test, it is found that aerobic high impact gymnastics have an effect on the improvement of cardiorespiratory endurance. Where the probability value ( $p$ ) is significant is 0,000 which means $0.000<0.05$ then there is a significant difference.
\end{abstract}

Keywords: Skipper, Cardiorespiratory Endurance, Aerobic High Impact Gymnastic

\section{PENDAHULUAN}

Arung jeram (rafting) merupakan aktivitas pengarungan aliran sungai yang berjeram atau riam dengan menggunakan sarana seperti perahu karet, kayak, dan kano. Kegiatan arung jeram merupakan perpaduan antara petualangan, olahraga, dan edukasi. Orang yang baru melakukan kegiatan arung jeram biasanya tidak diperbolehkan mengarungi jeram tanpa seorang skipper (kapten kapal) agar resiko yang terjadi bisa dikurangi atau dicegah. Skipper adalah seorang yang mengatur 
arah perjalanan perahu dan bertanggung jawab atas lajunya perahu serta keselamatan para penumpang perahunya ${ }^{1}$.

Sebelum berarung jeram banyak persiapan yang harus dilakukan oleh skipper mulai dari persiapan alat-alat sampai memberikan arahan kepada wisatawan sebelum melakukan pengarungan sungai. Untuk menuju point start arung jeram, skipper juga harus menuruni ratusan anak tangga kemudian melakukan pengarungan sungai yang berjarak $12 \mathrm{~km}$ dengan waktu tempuh selama 2 jam. Sesampai di finish, skipper harus menaiki seratus anak tangga agar bisa sampai pada titik penjemputan. Kegiatan tersebut dilakukan berulangberulang sampai 4-5 kali yang menyebabkan tingginya kerja fisik dan kelelahan yang dialami oleh skipper.

Salah satu komponen kebugaran fisik yaitu: daya tahan kardiorespirasi ${ }^{2}$. Daya tahan kardiorespirasi merupakan kesanggupan sistem jantung, paru, dan pembuluh darah untuk bekerja secara optimal baik pada saat istirahat maupun bekerja dalam mengambil oksigen dan menyalurkanke jaringan aktif sehingga dapat digunakan sebagai proses metabolisme dalam tubuh.

Tipe atau jenis olahraga yang paling tepat untuk meningkatkan daya tahan kardiorespirasi, termasuk juga kebugaran fisik (kesegaran jasmani) salah satunya adalah senam aerobik ${ }^{4}$. Senam Aerobik adalah latihan fisik yang bertujuan untuk meninngkatkan efisiensi pemasukan oksigen ke jaringan tubuh yang dipadukan dengan irama musik pada durasi tertentu ${ }^{5}$. Senam aerobik high impact merupakan bagian senam aerobik berdasarkan gerakan senam aerobic high impact memiliki ciri khas dengan irama tubuh yang cepat dengan diiringi oleh musik yang berirama cepat dan gerakan dinamis ${ }^{6}$.

Berdasarkan latar belakang diatas, rumusan masalah dalam penelitian ini “apakah pemberian latihan senam aerobic high impact dapat meningkatkan daya tahan kardiorespirasi pada skipper arung jeram?".

Penelitian ini bertujuan untuk mengetahui pemberian pemberian latihan senam aerobic high impact dapat meningkatkan daya tahan kardiorespirasi pada skipper arung jeram.

Manfaat yang didapat dalam penelitian ini adalah memberikan pengetahuan sejauh mana senam aerobic high impact dapat meningkatkan daya tahan kardiorespirasi pada skipper arung jeram.

\section{METODE}

\section{A. Ruang Lingkup Penelitian}


Penelitian dilaksanakan di My Adventure Rafting yang bertempat di Desa Carangsari, Kecamatan Petang, Kabupaten Badung, Propinsi Bali pada bulan Mei-Juni. Subjek diberikan latihan senam aerobic high impact sebanyak 3x dalam seminggu dan dilakukan selama 4 minggu. Rancangan Penelitian adalah Pre Test and Post Test Design.

\section{B. Populasi dan Sampel}

Populasi penelitian adalah skipper yang bekerja di My Adventure Rafting, Desa Carangsari, Kabupaten Badung. Jumlah subjek dalam penelitian ini adalah sebanyak 21 orang yang memenuhi kriteria sebagi berikut: skipper yang bekerja pada My Adventure rafting, tidak sedang mengidap penyakit pada sistem kardiorespirasi dan mampu berkomunikasi secara aktif.

\section{Pengumpulan Data}

Pengumpulan data dilakasnakan sebelum dan sesudah diberikan latihan senam aerobic high impact. Untuk mengukur daya tahan kardiorespirasi para skipper dilakukan pengukuran dengan menggunakan Harvard Step Test.

\section{Analisis Data}

Analisis data yang dilakukan sebagai berikut:
1. Analisis deskriptif nilai Harvard Step Test.

2. Uji Normalitas data menggunakan Shapiro-wilk test.

3. Analsisi efek perlakuan menggunakan Paired Sample test.

\section{HASIL dan PEMBAHASAN}

Tabel 1

Karakteristik Subjek Penelitian

\begin{tabular}{llll}
\hline Karakteristik & & \multicolumn{2}{l}{$\begin{array}{l}\text { Kelompok } \\
(\mathrm{n}=21)\end{array}$} \\
\cline { 3 - 4 } & & $\mathrm{n}$ & $\%$ \\
\hline umur & $20-25$ & 10 & 47,6 \\
& $26-31$ & 3 & 14,3 \\
& $32-37$ & 4 & 19,0 \\
& $38-43$ & 2 & 9,5 \\
& $44-49$ & 2 & 9,5 \\
\hline
\end{tabular}

Sumber: (Data Primer,2017)

Berdasarkan Tabel 1 dapat dilihat karakteristik umu dari subjek penelitian. Umur 20-25 tahun berjumlah 10 orang (47,6\%), umur 26-31 tahun berjumlah 3 orang (14,3\%), umur 32-37 tahun berjumlah 4 orang $(19,0 \%)$, umur $38-43$ tahun berjumlah 2 orang $(9,5 \%)$, dan umur 44-49 tahun berjumlah 2 orang $(9,5$ $\%)$. 
Tabel 2

Deskriptif Pengukuran Daya

Tahan Kardiorespirasi Menggunakan

Harvard Step Test Sebelum dan Sesudah

\section{Perlakuan}

\begin{tabular}{llll}
\hline $\begin{array}{l}\text { Nilai } \\
\text { Harvard } \\
\text { Step Test }\end{array}$ & & $\begin{array}{l}\text { Kelompok } \\
(\mathrm{n}=21)\end{array}$ & \\
\hline & sebelum & sesudah & peningkatan \\
\cline { 2 - 4 } Min & 33 & 55 & \\
Max & 42 & 62 & \\
& & & $54 \%$ \\
Rerata & 37,52 & 58,14 & \\
SD & 2,421 & 2,032 & \\
\hline
\end{tabular}

Berdasarkan Tabel 2 dapat dilihat nilai rerata sebelum melakukan latihan adalah 37,52 dan nilai rerata sesudah melakukan latihan adalah 58,14. Peningkatan rerata daya tahan kardiorespirasi sebelum dan sesudah melakukan latihan sebesar $54 \%$.

\section{UJI NORMALITAS DATA}

Tabel 3

\section{Uji Normalitas Nilai Harvard Step Test}

\begin{tabular}{lc}
\hline \multirow{2}{*}{ Nilai Harvard Step Test } & $\begin{array}{c}\text { Saphiro wilk test } \\
(p)\end{array}$ \\
\cline { 2 - 2 } & Perlakuan \\
\hline Sebelum perlakuan & 0,349 \\
Sesudah perlakuan & 0,297 \\
\hline Sumber: (Data Primer,2017) \\
Pada Tabel 3 didapatkan nilai p \\
sebelum perlakuan sebesar 0,349 dan nilai \\
p sesudah perlakukan sebesar 0,297.
\end{tabular}

Kedua nilai tersebut nilainya lebih besar dari 0,05 sehingga dapat dinyatakan data berdistribusi normal.

PENGUJIAN NILAI HARVARD STEP TEST SEBELUM DAN SETELAH PELATIHAN

Tabel 4.

\section{Uji Hipotesis Nilai Hardvard Step Test sebelum dan sesudah pelatihan}

\begin{tabular}{llll}
\hline \multirow{2}{*}{ perlakuan } & Mean & \multicolumn{2}{c}{$\begin{array}{c}\text { Paired sample } \\
\text { test }\end{array}$} \\
\cline { 3 - 4 } & & $\mathrm{t}$ & $\mathrm{p}$ \\
\hline sebelum & 37,52 & 64,476 & 0,000 \\
sesudah & 54,14 & & \\
\hline
\end{tabular}

Tabel 4 menunjukkan bahwa nilai uji hipotesis Harvard Step Test sebelum dan sesudah diberikan latihanyang dilakukan analisis dengan menggunakan Paired Sample Test menunjukkan nilai $\mathrm{p}=0,000$. Hasil ini menyatakan bahwa secara signifikan pemberian latihan senam aerobik high impact dapat meningkatkan daya tahan kardiorespirasi pada skipper arung jeram.

Terjadi peningkatan daya tahan kardiorespirasi pada skipper arung jeram di My Adventure Rafting setelah diberikan latihan senam aerobic high impact dengan frekuensi $3 \mathrm{x} / \mathrm{minggu}$, intesitas tinggi, cepat, dan dinamis, dan waktunya 20-30 menit. Olahraga aerobik yang dilakukan dapat mencapai sasaran yang tepat dengan tujuan yang jelas, maka olahraga yang 
dilakukan harus sesuai dengan dosis yang tepat. Dosis olahraga terdiri dari intesitas, frekuensi, durasi, dan model latihan yang sering dikenal dengan FITT, yaitu Frequency, Intensity, Time, dan Type ${ }^{7}$.

Daya tahan kardiorespirasi pada skipper dapat meningkat apabila diberikan latihan yang sesuai dengan ketentuan dosis yang telah di tentukan. Seperti data yang ada pada tabel 2 mengenai hasil pengukuran daya tahan kardiorespirasi sebelum diberikan perlakuan dan sesudah diberikan perlakuan latihan senam aerobic high impact sebanyak 3 kali latihan dalam seminggu selama 4 minggu nampak peningkatan yang signifikan dari daya tahan kardiorespirasi.

Peningkatan hasil latihan fisik tejadi minimal pada periode waktu 4-6 minggu dan akan menurun setelah latihan fisik dihentikan ${ }^{8}$. Ketika beraktifitas fisik jantung melakukan dua fungsi yaitu memompa lebih cepat serta mengirim darah lebih banyak setiap memompa ${ }^{9}$ Pada saat pemberian latihan, pada jantung terjadi peningkatan kebutuhan oksigen serta hasil pembuangan di sel - sel otot. Jantung akan memompa lebih banyak darah dan hasil pembuangan akan dibawa ke jantung lebih banyak.

Peningkatan daya tahan jantung paru sesuai dengan penelitian Osanloo yaitu terjadi peningkatan daya tahan jantung paru pada wanita melalui peningkatan $\mathrm{VO} 2$ Max setelah melakukan latihan aerobic. Latihan aerobic pada penelitian Osanloo berupa kombinasi antara senam aerobic dengan step training ${ }^{10}$. Aktivitas aerobik akan meningkatkan fungsi jantung dan paru akibat mekanisme adaptasi jantung dan paru oleh karena kebutuhan oksigen yang meningkat selama senam aerobik. Meningkatnya fungsi jantung dan paru meningkatkan daya tahan jantung paru yang berarti juga peningkatan kebugaran fisik.

\section{KESIMPULAN}

Berdasarkan hasil analisis penelitian didapatkan kesimpulan bahwa latihan senam aerobik high impact dapat meningkatkan daya tahan kardiorespirasi pada skipper arung jeram.

\section{DAFTAR PUSTAKA}

1. Darsono dan Setra. 2008. Olahraga Alam. Jakarta. Perca

2. Ari Santoso, Danang. 2016. Analisis Tingkat Kebugaran Jasmani Atlet Bolavoli Putri Universitas Pgri Banyuwangi. Jurnal Kejaora. ISSN 2503-2976, Volume 1 Nomor 1.

3. Fridami Dewi, A. A. 2016. Daya Tahan Kardiorespirasi Siswa Pemain Basket Sekolah Menengah Atas Di Kota Denpasar Lebih Baik Dari Pada Siswa Bukan Pemain Basket.E-Jurnal Medika, Vol. 5 No.4, April, 2016. 
4. Giriwijoyo, S. \& Sidik, Zafar. 2012. Ilmu Faal Olahraga (fisiologi olahraga). Bandung : PT Remaja Rosdakarya.

5. Candrawati,2016. Senam Aerobik Meningkatkan Daya Tahan Jantung Paru dan Fleksibilitas.Jurnal Kedokteran Brawijaya,Vol. 29, No. 1,Februari 2016.

6. Yudha Febrian, 2015. Kebugaran Kardiorespirasi Pemain Ukm Sepakbola Universitas Muhammadiyah Purwokerto 2015. Jurnal Dinamika Pendidikan Dasar. Volume 7, No 2, September 2015: 10 - 20.

7. Siswantoyo, 2008.Sport Medicine Dan Permasalahannya. Dalam Proceding Seminar Olahraga Nasional Ke II. Yogyakarta: FIK Universitas Negeri Yogyakarta, 123-13.

8. Puji ,2007. Pengaruh Latihan Fisik; Senam Aerobik Terhadap Penurunan Kadar Gula Darah Pada Penderita Dm Tipe 2 di Wilayah Puskesmas Bukateja Purbalingga.Media Ners, Volume 1, Nomor 2, Tahun 2007, hlm 49 - 99.

9. Corbin, B, Charles, C.B, Le Masurier, G. 2014. Fitness for Life.Human Kinetics.Sixth Edition.Human Kinetics. USA. P.58 - 64.

10. Osanloo P, Najar L, Zafari A. 2012. The Effects of Combined Training (Aerobic Dance, Step Exercise and Resistance Training) on Body Composition in Sedentary Females.Annal of Biological Research. 